\title{
Finite Element Analysis of FRP Strengthened Masonry Walls Subject to In-Plane Loading
}

\author{
Samuel A. Babatunde \\ Department of Civil and Coastal Engineering, University of Florida, Gainsville, USA
}

Email address:

samuel.babatunde@ufl.edu

\section{To cite this article:}

Samuel A. Babatunde. Finite Element Analysis of FRP Strengthened Masonry Walls Subject to In-Plane Loading. Science Research. Vol. 5, No. 3, 2017, pp. 23-35. doi: 10.11648/j.sr.20170503.12

Received: February 28, 2017; Accepted: May 4, 2017; Published: July 31, 2017

\begin{abstract}
Interest in the application of Fiber Reinforced Polymer (FRP) for strengthening of masonry buildings has been growing steadily due to their ease of application and favorable structural at tributes. Some of these structural attributes include high ductility, stiffness, corrosion resistance and low weight. Studies have shown that FRP composites can improve the lateral resistance of un- reinforced masonry (URM) walls significantly. Analytical models and numerical calculations using finite element models developed for both cross and grid configurations of FRP strengthening are discussed in this paper. Different FRP strips are applied along the wall diagonals in the form of "X" shape and vertically and horizontally along the wall on one side. The walls were subjected to in-plane loading. Results showed that the application of FRP strips modified the static behavior of the walls due to transfer of tensile stresses from masonry to the FRP strips.
\end{abstract}

Keywords: FRP, Strengthening, Masonry

\section{Introduction}

Several studies have shown that FRP strengthening of masonry walls can increase the out-of plane resistance of unreinforced masonry (URM) walls. However, there are very few studies done on the impact FRP strengthening on in-plane loading of URM walls. ElGawady et al. [5] conducted simulated earthquake tests on six half-scale URM specimens. Different types of FRP composites and configurations were used to upgrade the specimens. The specimens were subjected to simulated earthquake motions on an earthquake simulator. They reported that FRP strengthening improved the lateral resistance of the wall by a factor of $1.3-2.9$. They also observed debonding of the FRP at $50 \%$ to $80 \%$ of the ultimate load resistance. In a series of cyclic tests performed on URM walls, Schwegler [14] reported an increase of about 1.7 in the in-plane resistance of the walls.

$\mathrm{Yu}$ et al. [21] used Polyurea to increase the in-plane resistance of URM walls. Abrams and Lynch [2] observed an increase of a factor of 3 in in-plane resistance of URM walls subjected to in-plane loading in their study. Others such as Tumialan et al. [18], Hamid et al. [7] and Li et al. [9] have shown that FRP composites can improve the shear capacities of URM walls significantly. Haroun et al. [8] conducted an experimental program on six full-scale masonry block walls. One wall was used as control and the other wall was cracked for investigating repair techniques. The other four wall specimens were strengthened with unidirectional carbon/epoxy on one or two sides or E-glass /epoxy FRP laminates on one side of the wall. The walls were subjected to a combination of constant axial load and incremental lateral cyclic (in-plane) loads. The result of the study showed significant increase in strength, stiffness and ductility for the FRP strengthened walls.

Further investigations into the shear performance of masonry walls reinforced with carbon fiber reinforced polymer (CFRP) were conducted by Alcaino and Santa-Maria [3]. In the study, sixteen clay brick walls were subjected to in-plane cyclic loading in conjunction with a simultaneous constant vertical load. Thirteen walls with shear reinforcement (NSRM) and without shear reinforcement (SRM) were retrofitted with unidirectional carbon fiber sheets bonded to both sides of the walls with adhesive in cross and grid layout configurations. Three walls were not retrofitted at all. The authors reported an increase in shear strength of $49-84 \%$ in retrofitted NSRM walls and $13-34 \%$ increase in SRM retrofitted walls. Furthermore, the authors reported a larger increase in shear strength and corresponding displacement for 
walls with cross layout configurations. Dynamic testing by Turek et al. [19] on eight full scale concrete block walls strengthened with four configurations of glass fiber reinforced polymer (GFRP) strips to simulate design basis and beyond design basis earthquake loading showed that all the retrofitted walls performed well during design basis earthquake loading and three of the four GFRP configurations performed well during beyond design basis earthquake loading. Valluzzi et al. [20] in the same context conducted an experimental study on the efficiency of FRP for shear reinforcement for masonry panels. In the study, various FRP configurations were analyzed for diagonal compression tests. A significant increase in masonry strength was reported. Based on the results of these studies, it can be concluded that strengthening with FRP strips positively increase the in-plane shear capacity of load bearing masonry walls. The in-plane shear resistance of load-bearing URM walls is provided by the shear bond strength of the mortar and frictional shear due to vertical load. Due to deteriorated conditions and aging, the mortar joints may suffer significant loss of shear capacity. During a beyond design basis earthquake loading, the shear capacity of the mortar is exceeded resulting in failure. Therefore an effective method of analysis is needed to qualify and strengthen load-bearing URM walls.

\section{Design Considerations}

As a result of the multiaxial nature of ground shaking during seismic events, masonry walls will be subjected to simultaneous vertical, in-plane and out- of- plane response. The in-plane response of the wall will be a result of the resistance of the wall to inertia forces from the floor masses and other parts (Paulay and Priestley [13]). This will result in bending and shear stresses in the walls. When the stresses exceed the elastic range of an unreinforced masonry walls, the induced inertia forces may cause serious damage to the building (Tomazevic [17]). Furthermore, at higher stresses extensive stress redistribution occurs due to nonlinear material behavior in mortar joints and loss of bond between mortar and brick culminating in failure (Page [12]).

Tomazevic [17] has shown that the modes of failure in an unreinforced masonry wall subjected to in-plane loading is characterized by sliding shear failure, diagonal cracking and flexural failure. These failure modes are shown in Figure 1.

Sliding shear failure and diagonal cracking are the two most common. In both cases a slip occurs along the bed joint which controls the failure pattern. Tests conducted by Lourenco [11] have revealed that the shear strength (in-plane shear resistance) of a masonry bearing wall for slip failure mode is given by:

$$
\boldsymbol{\tau}_{\mathrm{b}}=\boldsymbol{v}_{\mathrm{bo}}+\boldsymbol{\mu} \boldsymbol{\sigma}_{\mathrm{y}}
$$

Where $\boldsymbol{\tau}=$ shear stress at the shear bond failure; $\boldsymbol{v}_{\text {bo }}=$ shear bond strength at zero normal stress due to the adhesive strength of mortar; $\mu=$ coefficient of friction between brick and mortar; $\boldsymbol{\sigma}_{\mathrm{y}}=$ normal stress.

According to Tomazevic [17], the mechanics of the failure modes depend on several factors such as boundary restraints, quality of the masonry materials, wall geometry, and load acting on the wall. Failure may also occur in masonry joints if the tensile or shear bond strength is exceeded. Hence, masonry may be considered as a two-phase material consisting of elastic bricks set and inelastic mortar matrix. For an FRP strengthened wall, subjected to in-plane loading, the failure mode is characterized by; i) FRP debonding, from shear transfer at the FRP/masonry interface, ii)

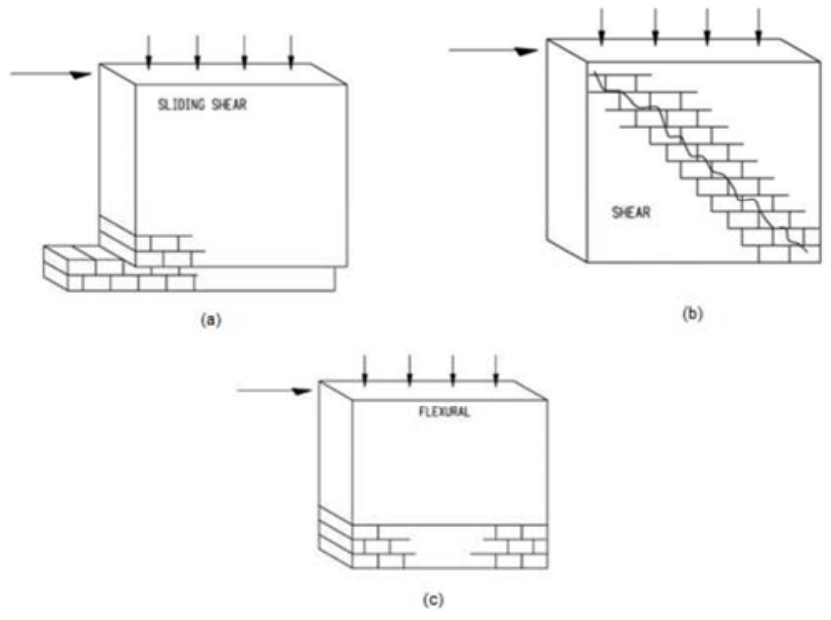

Figure 1. (a) Sliding shear failure, (b) diagonal shear failure (c) flexural shear failure (Tomazevic, [17]).

Flexural failure due to either FRP rupture or masonry crushing and iii) Shear failure due to either sliding shear or diagonal shear failure (Garbin et al. [6]). The application of FRP laminates modifies the static behavior of URM walls since the fibers bear the tensile stresses thus modifying the failure mode from brittle to ductile failure.

\section{Design Scope}

The objective of this paper is to study the behavior of unstrengthened and FRP strengthened masonry walls subjected to in-plane loading using the finite element analysis method. Unreinforced masonry walls are strengthened with carbon fiber reinforced polymer (CFRP), glass fiber reinforced polymer (GFRP) and aramid fiber reinforced polymer (AFRP) laminates using three upgrading configurations. (horizontal and vertical grid pattern and diagonal " $X$ " pattern). Both strengthened and unstrengthened walls are subjected to in-plane loads and their behaviors up to the ultimate conditions are compared numerically using the commercial software ABAQUS (ABAQUS, [1]).

\section{Computer Modeling of FRP-Strengthened Walls}

The behavior of FRP-strengthened masonry walls subjected to in-plane loading has been investigated by full-scale experimental programs (ElGawady et al [5]). However, finite element analysis can also be used to model the behavior 
numerically to corroborate the experimental results and provide invaluable supplement to the laboratory experiments. The finite element analysis method predicts the behavior of a structure by dividing it into a number of simple elements each of which has its own physical and mechanical properties. Due to the anisotropic and nonhomogeneous nature of masonry, it is quite challenging to model its behavior using finite element analysis.

Within the past decade, researchers have attempted to simulate the behavior FRP-strengthened masonry using the finite element method (Lourenco [11], Lopez et al. [10]. Smeared and discrete-crack approaches have been developed to evaluate the shear resistance of masonry walls (Shing et al. [15]. In these approaches, cracking of the masonry occurs when the principal tensile stress exceeds the ultimate tensile strength. The elastic modulus is assumed to be zero in the direction parallel to the principal tensile stress (Suidan and Schnobrich [16])). It has been reported (Shing et al. [15] that these approaches compared well with experimental results and the different failure mechanisms from ductile to brittle can be simulated. Concrete beams strengthened with FRP laminates were tested in the laboratory. Finite element analysis with the smeared cracking approach was used to simulate the behavior and failure mechanism of the beams. The experimental and numerical models showed good agreement.

Lourenco [11] proposed three modeling strategies for masonry structures namely; i) detailed micro-modeling in which units and mortar in the joints are represented by continuum elements and the unit-mortar interface is represented as discontinuous elements, ii) simplified micro-modeling in which the masonry units are represented as continuum elements and the mortar joints and unit- mortar interface is lumped as discontinuous elements, iii) macro-modeling where units, mortar and unit-mortar interface are smeared out in the continuum. The modeling strategies are shown in Figure 2.

In the micro-modeling approach, the Youngs modulus, Poissons ratio and inelastic properties of both unit and mortar are considered in the analysis. The interface is modeled as a crack/slip plane with dummy stiffness to prevent permeation of the continuum. This way, the composite action of the unit, mortar and interface can be examined. For the simplified micro-modeling approach, masonry is considered as a set of elastic blocks bonded by potential fracture/slip lines at the interface.

(a)

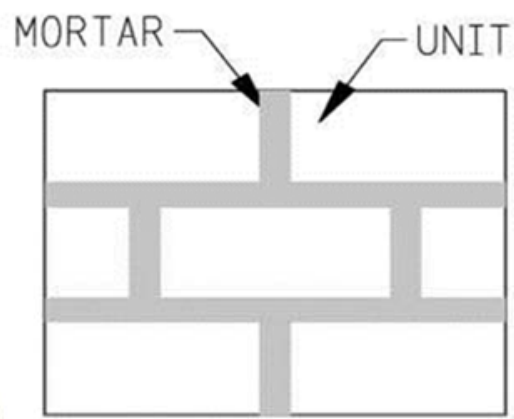

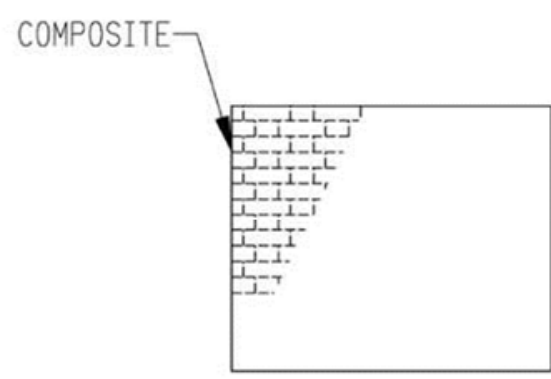

(b)

(c)

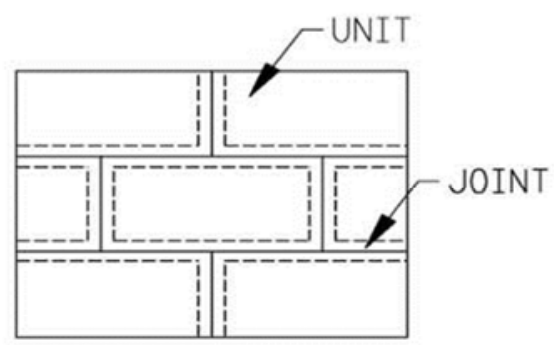

Figure 2. Modeling strategies for masonry structures (a) detailed micro-modeling; (b) simplified micro modeling; (c) macro-modeling (Lourenco, 1998).

This is accomplished by lumping each joint (which consists of mortar and two unit-mortar interfaces) into an average interface and the units are expanded to maintain geometry. The Poissons effect of the mortar is not considered in the analysis and this affects the accuracy of this modeling approach. In essence, a large number of parameters such as the properties of bricks and mortar, the geometry of the bricks, the joint arrangement, and the interface occurrences are employed in a developing a micro model. As a result, the use of micro models for analyzing the global behavior of a masonry building is cost prohibitive due to the large number of elements generated.

The macro-modeling approach treats masonry as a homogeneous anisotropic continuum. Since it does not distinguish between individual units and joints, the parameters used in the analysis must be representative of the entire wall. This is the basis of the homogenized anisotropic model proposed by Lopez et al. [10] and used in this study. The macro-modeling approach was selected for numerical simulation due to the need to understand the global resisting mechanisms of masonry walls.

The model is based on compatibility and equilibrium of a basic cell of masonry under different loading conditions. The basic cell is shown in Figure 3 below. The notations used in the constitutive equations provided by Lopez et al. [10] for the stress-strain behavior of the composite are also shown in the figure.

The objective of this paper is to evaluate the reliability of a finite element modeling technique developed with commercial software in analyzing the behavior of an unreinforced and FRP rein-forced masonry wall subjected to in-plane loading. 


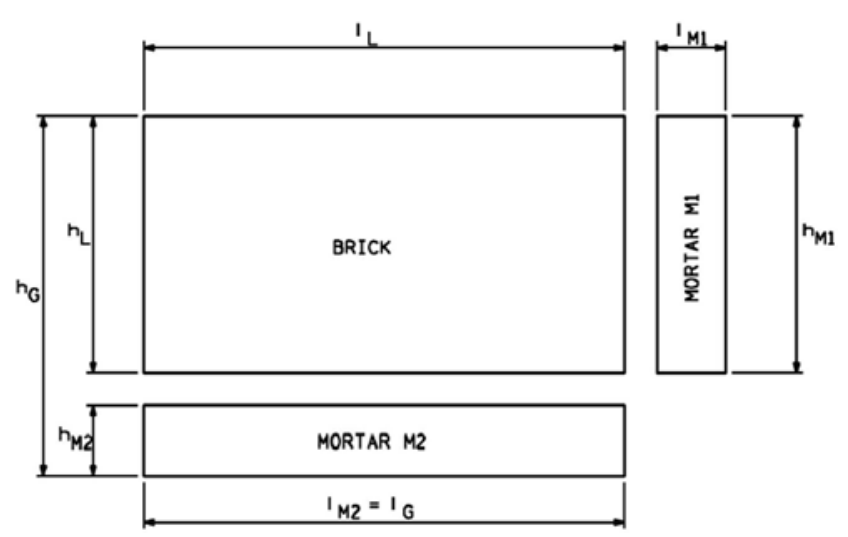

Figure 3. Basic cell homogenized masonry (Lopez et al, 1999).

\section{Methodology}

Numerical Analysis of Masonry Walls Strengthened with FRP Laminates

According to Ehsani and Valazquez-Dimas [4] retrofitting with FRP composites may improve the shear resistance of walls subjected to in plane loading as follows:

$$
\boldsymbol{\tau}_{\mathrm{b}}=\boldsymbol{v}_{\mathrm{bo}}+\boldsymbol{\mu} \boldsymbol{\sigma}_{\mathrm{y}}+\boldsymbol{\tau}_{\mathrm{FRP}}
$$

Where:

$\boldsymbol{\tau}_{\mathrm{b}}$ - shear stress at the shear bond failure

$\boldsymbol{v}_{\text {bo }}$ - shear bond strength at zero normal stress due to adhesive strength of mortar

- coefficient of friction between brick and mortar normal stress

$\boldsymbol{\tau}_{\text {FRP }}=$ contribution of the FRP composite in resisting shear.

In this study walls with dimensions of $9 \mathrm{~m} \times 4.5 \mathrm{~m} \times 0.106 \mathrm{~m}$ are strengthened with carbon fiber

reinforced polymer (CFRP), glass fiber reinforced polymer (GFRP), and aramid fiber reinforced polymer (AFRP) and subjected to various horizontal in-plane loadings. Geometry and boundary conditions for the analyzed walls is shown in Figure 4.

The behavior of unreinforced hollow brick masonry walls and hollow brick masonry walls rein- forced with carbon, glass and aramid fiber polymers are simulated using ABAQUS 6.1.4 software. The mechanical properties used in the models are obtained from manufacturers. The objective is to predict is to predict the global behavior unreinforced and FRP reinforced masonry walls subjected to in-plane loading.

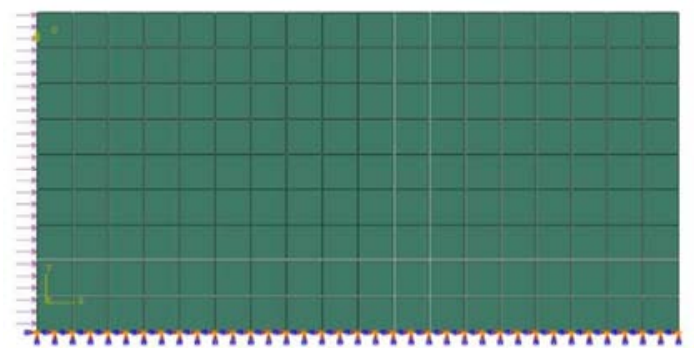

Figure 4. Geometry, boundary conditions and loading on masonry wall.

\section{Finite Element Modeling}

\subsection{Finite Element Modeling of the Unreinforced Masonry Wall}

\subsubsection{Finite Element Modeling of the Mortar}

In this analysis the masonry wall is considered as a two component structure namely bricks and mortar. The mortar bound the bricks together and since they behave differently from the bricks they are modeled as cohesive elements.

Table 1. Mohr-Coulomb Parameters for Mortar.

\begin{tabular}{ll}
\hline Cohesion, c & $0.42 \mathrm{MPa}$ \\
Coefficient of Friction, $\boldsymbol{\mu}$ & 0.49 \\
Dilatancy Coefficient, ${ }^{\tan (\boldsymbol{\theta})}$ & 0.52 \\
Shear Fracture Energy, $\mathrm{G}_{\mathrm{f}}$ & $2.0 \mathrm{~N} / \mathrm{mm}$ \\
\hline
\end{tabular}

Table 2. Properties of Brick Masonry.

\begin{tabular}{ll}
\hline Modulus of Elasticity, E & $6.2 \mathrm{KPa}\left(0.9 \times 10^{6} \mathrm{psi}\right)$ \\
Poisson's Ratio, v & 0.19 \\
Compressive Strength, $\mathrm{f}_{\mathrm{cu}}$ & $17.2 \mathrm{MPa}(2500 \mathrm{psi})$ \\
Tensile Strength, $\mathrm{f}_{\mathrm{tu}}$ & $0.29 \mathrm{MPa}(42 \mathrm{psi})$ \\
\hline
\end{tabular}

This constitutive law for modeling the mortar joint is elastic- plastic and follows the Drucker-Prager (1952) formulation. Two Finite Element Methods (FEM) techniques were investigated for modeling the mortar. The two techniques utilized the Mohr-Coulomb mechanical parameters for mortar which are obtained from previous research studies. The mechanical properties are shown in Table 1 as follows:

The first approach considered was the use of thin layer of cohesive elements in the boundary between the bricks. However, this approach was judged inefficient due to the complexity of the model. In the second approach, the mortar was modeled as solid cohesive elements. This procedure was implemented in ABAQUS using the "Cohesive Behavior parameters, the screen shots of which are in Figure 5.

The size of the elements used for modeling the mortar is uniform with a thickness of $10 \mathrm{~mm}$ which represented the thickness of the joint.

\subsubsection{Finite Element Modeling of the Brick}

The three dimensional modeling of the brick was performed using 20 noded 3-D solid hexahedral elements with reduced integration as shown in Figure 6.

Material characterization in ABAQUS was done using elasto-plastic model with Youngs modulus, and Poissons ratio as elastic properties and the Ultimate and Yield strengths with the corresponding strains as plastic material properties. The whole structure was meshed using 150000 elements as shown in Figure 7 below. 

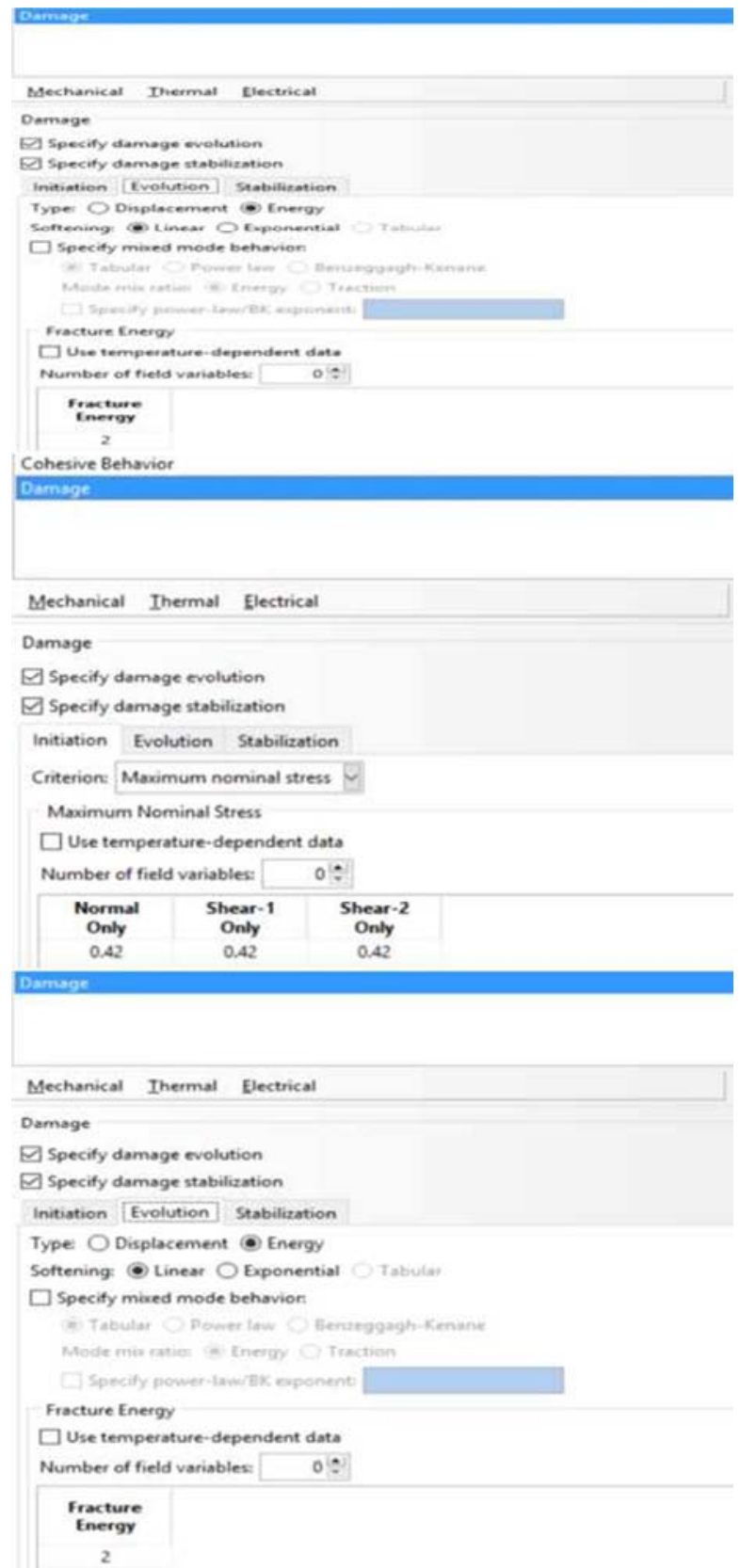

Figure 5. Screen shots.

\subsection{Finite Element Modeling of the Reinforced Masonry Wall}

A detailed modeling approach is used to simulate the behavior of the FRP strengthened masonry walls. In detailed modeling, the total structure of the masonry was considered. The bricks were considered as fully elastic, bonded together by mortar joint which was considered elasto-plastic. The FRP reinforcements are considered as tension-only elements and modeling was done by coupling the nodes of the elements of the masonry wall with the nodes of the elements of the FRP strips using tie constraints in ABAQUS. This created a perfect bond between the masonry and FRP elements. Modeling parameters for the FRP strips and the Adhesives modeled as ties are shown in Tables 3 and 4 respectively. The FRP strips were modeled in ABAQUS using the lamina material properties command that are specifically designed for modeling FRP composites. A screen shot of the input for CFRP in ABAQUS is shown in Figure 8 as an example.

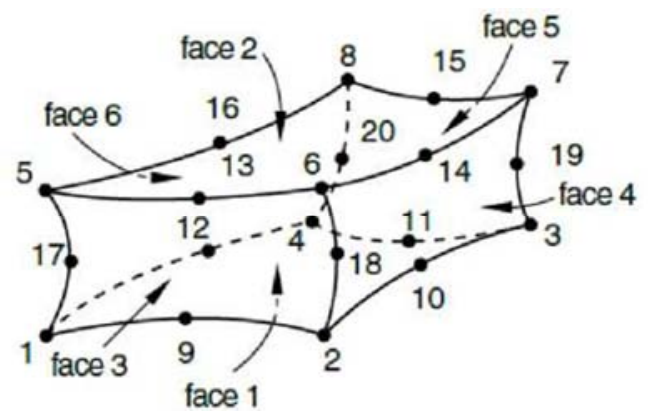

Figure 6. Applied Solid Elements Used for 3-D Modeling of Brick.

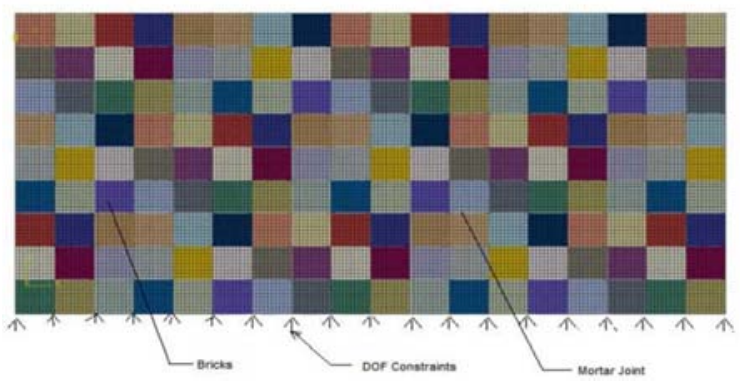

Figure 7. Meshing detail of the Masonry Wall.

\subsection{Grid Layout}

To study the behavior of masonry walls subject to in-plane loading, the following cases were considered:

a) Unstrengthened masonry wall

b) Masonry wall strengthened with CFRP, GFRP and AFRP horizontal grid laminates

c) Masonry wall strengthened with CFRP, GFRP and AFRP vertical grid laminates

d) Masonry wall strengthened with CFRP, GFRP and AFRP diagonal grid laminates

Table 3. Properties of Brick Masonry.

\begin{tabular}{llllll}
\hline Material & Width & Thickness & $\begin{array}{l}\text { Ultimate } \\
\text { Strength }\end{array}$ & $\begin{array}{l}\text { Elastic } \\
\text { Modulus }\end{array}$ & $\begin{array}{l}\text { Ultimate } \\
\text { Strain }\end{array}$ \\
\hline Carbon & $50 \mathrm{~cm}$ & $2 \mathrm{~mm}$ & $\begin{array}{l}2241 \mathrm{MPa} \\
(325 \mathrm{ksi})\end{array}$ & $\begin{array}{l}124 \mathrm{Gpa} \\
(18000 \mathrm{ksi})\end{array}$ & $1.81 \%$ \\
FRP & & $2 \mathrm{~mm}$ & $\begin{array}{l}896 \mathrm{Mpa} \\
(130 \mathrm{ksi})\end{array}$ & $\begin{array}{l}46 \mathrm{GPa} \\
(6700 \mathrm{ksi})\end{array}$ & $1.94 \%$ \\
Glass FRP & $50 \mathrm{~cm}$ & $2068 \mathrm{MPa}$ & $\begin{array}{l}74 \mathrm{GPa} \\
(10.73 \mathrm{ksi})\end{array}$ & $2.6 \%$ \\
$\begin{array}{l}\text { Aramid } \\
\text { FRP }\end{array}$ & $50 \mathrm{~cm}$ & $2 \mathrm{~mm}$ & $\begin{array}{l}200 \mathrm{ksi}) \\
(10.70\end{array}$ \\
\hline
\end{tabular}

Table 4. Epoxy Adhesive.

\begin{tabular}{ll}
\hline Tensile Strength & $33.8 \mathrm{Mpa}(4.900 \mathrm{ksi})$ \\
Elongation at break $(\%)$ & 1.2 \\
Young's Modulus & $3489 \mathrm{MPa}\left(5060 \times 10^{6} \mathrm{ksi}\right)$ \\
Flexural strength & $60.6 \mathrm{~Pa}(8.800 \mathrm{ksi})$ \\
Compressive Strength & $11,900 \mathrm{psi}(82.0 \mathrm{Mpa})$ \\
Compression $(\%)$ & \\
Elastic Modulus & $4820 \mathrm{GPa}(699080 \mathrm{ksi})$ \\
\hline
\end{tabular}




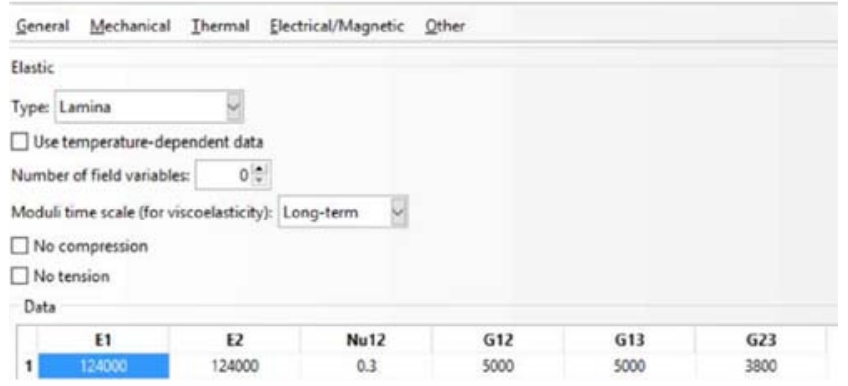

Figure 8. Screen Shot of Input Parameters for FRP Composites.

\subsubsection{Masonry Wall Strengthened with Various FRP Reinforcement Configurations}

The first con-figuration used in the analysis consisted of four (4) horizontal strips which are $500 \mathrm{~mm}$ wide spaced at a clear spacing of 500mm apart. Though the real thickness of the FRP composites were $1.4 \mathrm{~mm}, 0.35 \mathrm{~mm}$ and $0.33 \mathrm{~mm}$ for CFR, GFRP and AFRP respectively, a thickness of $2 \mathrm{~mm}$ was used in the analysis. In reality this could be could be achieved in the field by adding additional layers of laminates with hard rubber roller until a total thickness of $2 \mathrm{~mm}$ is achieved. This configuration was modeled with 21000 shell elements in ABAQUS. The actual model in ABAQUS is shown in Figure 9.

The second configuration used in the analysis consisted of nine (9) vertical strips which were $500 \mathrm{~mm}$ wide spaced at a clear spacing of $500 \mathrm{~mm}$ apart. This configuration was modeled with 25000 shell elements in ABAQUS. The actual model in ABAQUS is shown in Figure 10.

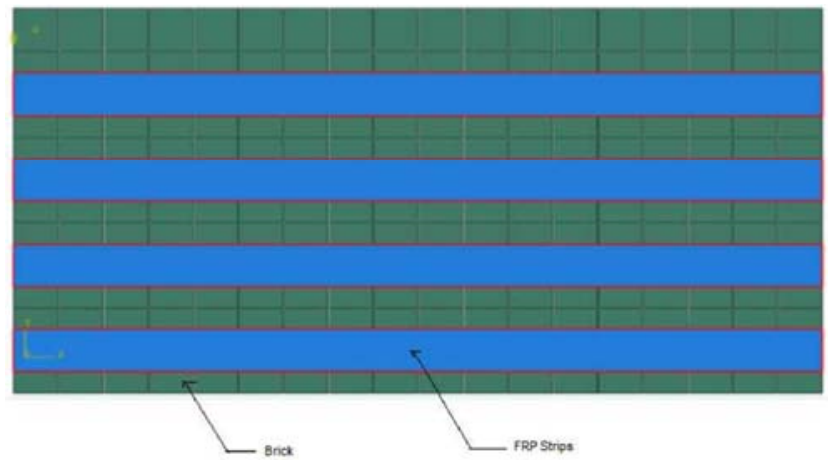

Figure 9. Wall strengthened with horizontal FRP Strips.

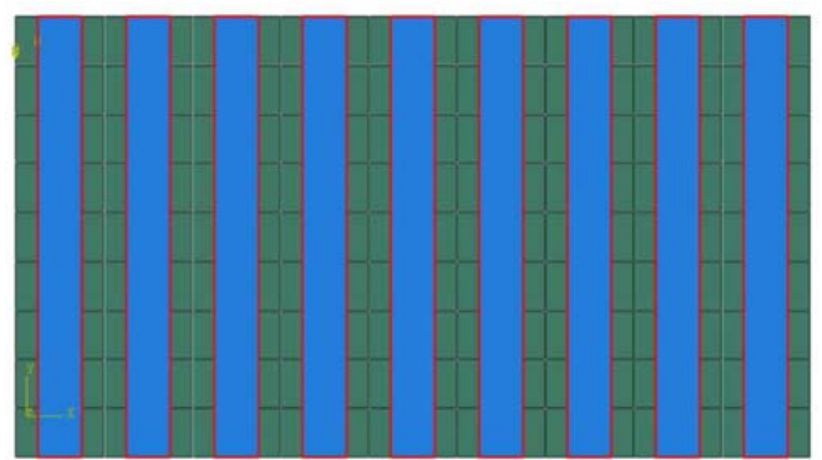

Figure 10. Wall strengthened with vertical FRP Strips.
The third configuration used in the analysis consisted of four (4) diagonal strips which formed $\mathrm{X}$ shapes that were $4500 \mathrm{~mm}$ apart. This configuration was modeled with 19000 shell elements in ABAQUS. The actual model in ABAQUS is shown in Figure 11.

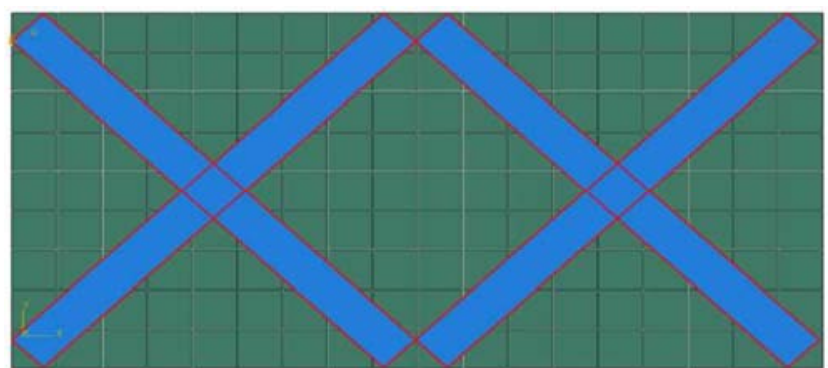

Figure 11. Wall strengthened with diagonal ' $X$ 'FRP Strips.

\subsubsection{Loading Conditions}

Three distinct load cases were considered and each model was subjected to horizontal uniformly distributed loads as shown in figures 12 through 21.

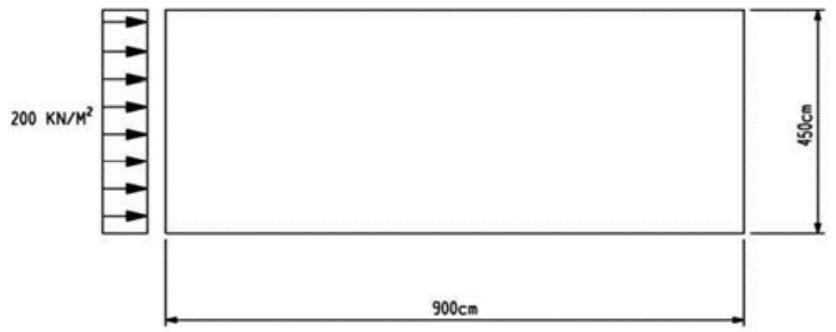

Figure 12. Load Case 1: 200KN/M2 Uniformly Distributed Load Applied to Unstrengthened Masonry Wall.

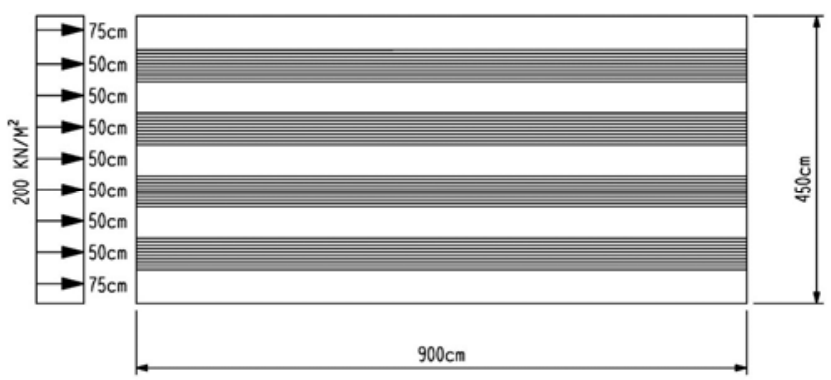

Figure 13. Load Casel: 200KN/M2 Uniformly Distributed Load Applied to Strengthened Masonry Wall with Horizontal grid 200 KN/M.

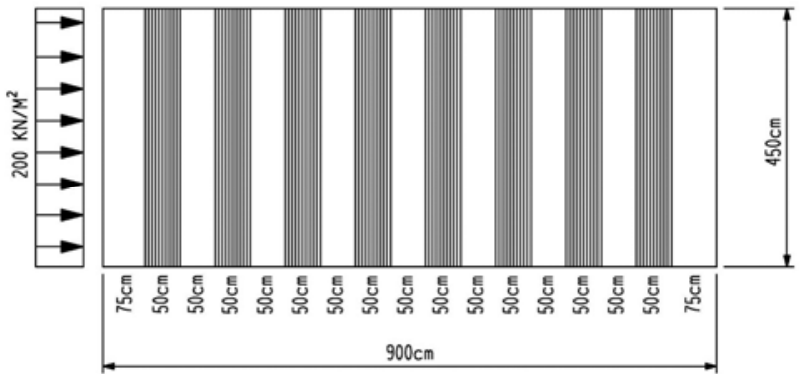

Figure 14. Load Case 1: 200KN/M2 Uniformly Distributed Load Applied to Strengthened Masonry Wall with Vertical grid. 


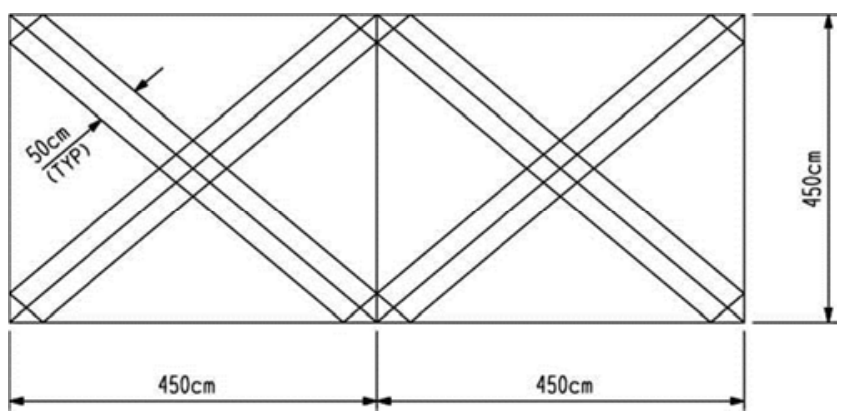

Figure 15. Load Case 1: 200KN/M2 Uniformly Distributed Load Applied to Strengthened Masonry Wall with Diagonal grid.

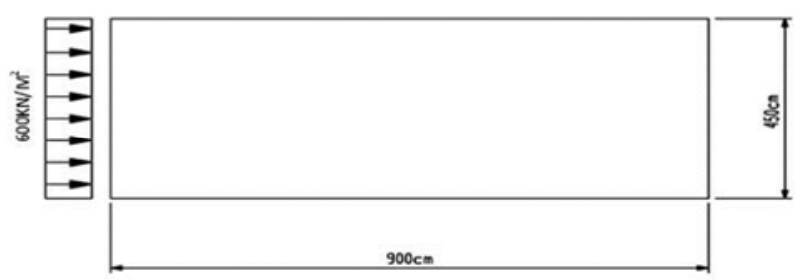

Figure 16. Load Case 2: 600KN/M2 Uniformly Distributed Load Applied to Unstrengthened Masonry Wall.

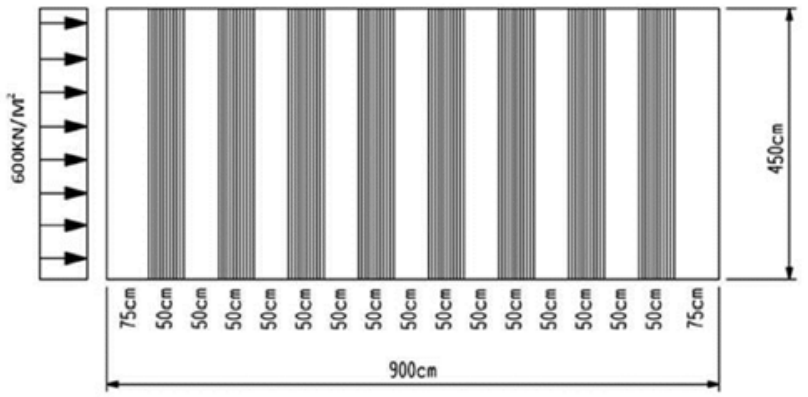

Figure 17. Load Case 2: 600KN/M2 Uniformly Distributed Load Applied to Strengthened Masonry Wall with Vertical grid.

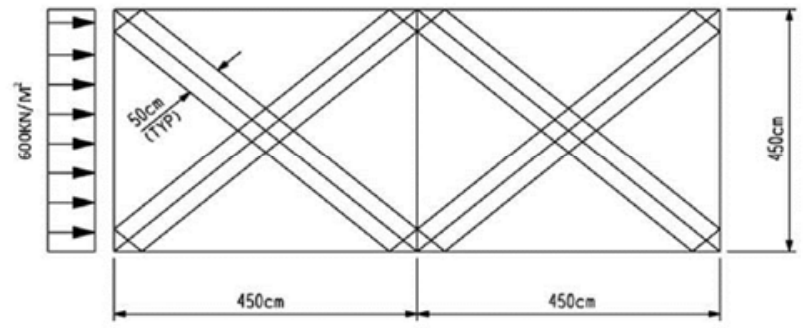

Figure 18. Load Case 2: 600KN/M2 Uniformly Distributed Load Applied to Strengthened Masonry Wall with Diagonal grid.

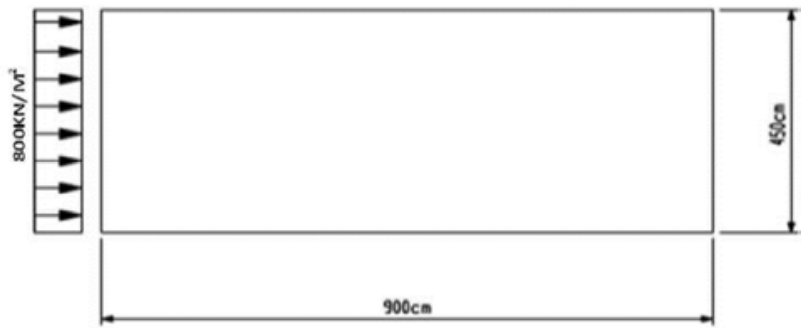

Figure 19. Load Case 3: $800 \mathrm{KN} / \mathrm{M} 2$ Uniformly Distributed Load Applied to Unstrengthened Masonry Wall.

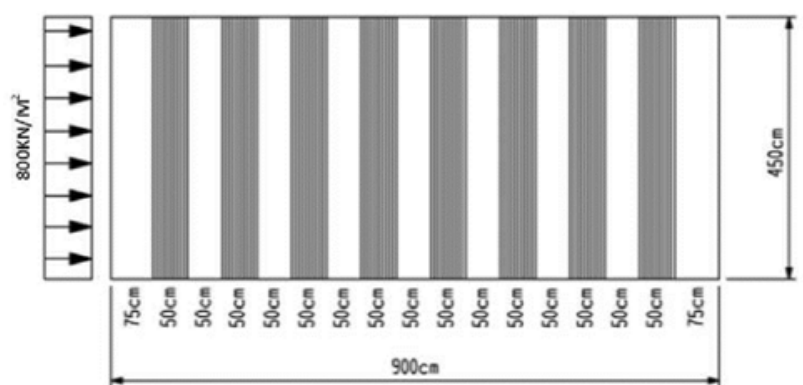

Figure 20. Load Case 3: 800KN/M2 Uniformly Distributed Load Applied to Strengthened Masonry Wall with Vertical grid.

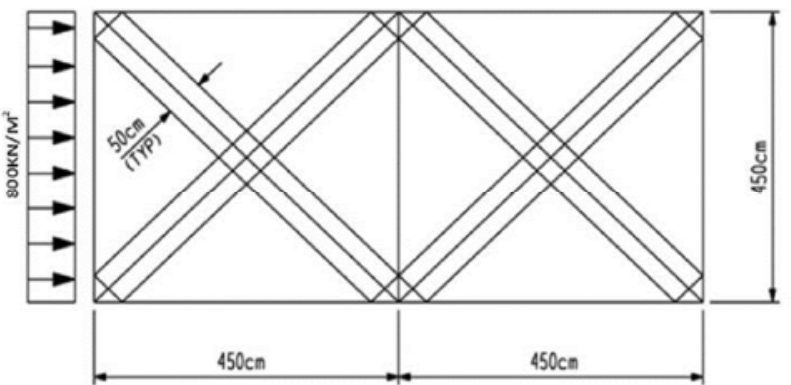

Figure 21. Load Case 3: 600KN/M2 Uniformly Distributed Load Applied to Strengthened Masonry Wall with Diagonal grid.

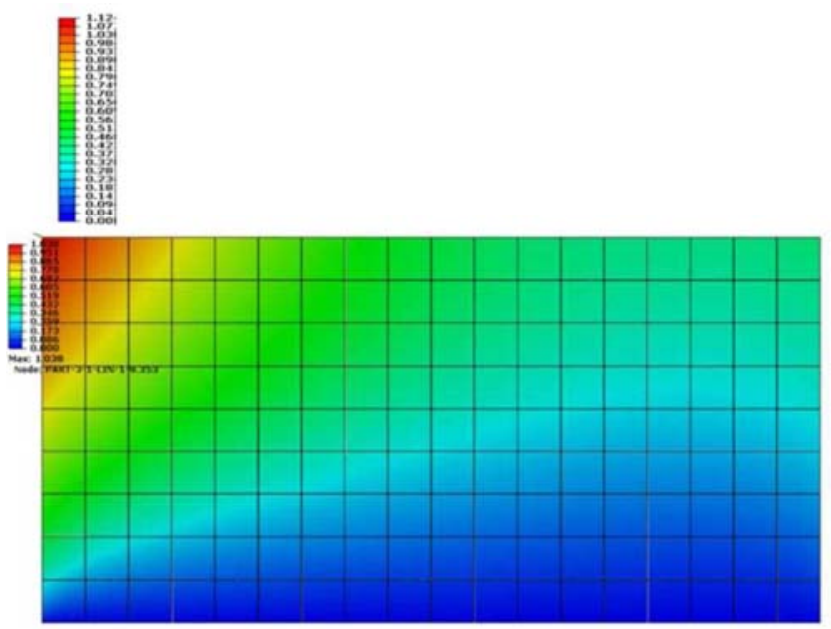

Figure 22. Stresses in Unreinforced Masonry Wall (MPa) subjected to a uniformly distributed load of 200KN/M2.

Note: In Figures 5-23 through 5-31 below, all walls are subjected to a uniformly distributed load of $200 \mathrm{KN} / \mathrm{M}^{2}$.

\section{Numerical Results and Discussions}

Results of stress distribution calculations are presented in Figures 22 through 51. The stress distribution for the unstrengthened masonry wall subjected to a uniformly distributed load of $200 \mathrm{KN} / \mathrm{M}^{2}$ is shown in Figure 22. Stress distribution calculations for the CFRP strengthened masonry wall subjected to a uniformly distributed load of $200 \mathrm{KN} / \mathrm{M}^{2}$ are shown in Figures 23 through 25. Stress distributions for a GFRP strengthened masonry wall subjected to a uniformly distributed load of $200 \mathrm{KN} / \mathrm{M}^{2}$ are shown in Figures 26 
through 28 while the stress distribution for a AFRP strengthened masonry wall are shown in Figures 29 through 31. In a similar fashion, stress distribution for the unstrengthened masonry wall subjected to a uniformly distributed load of $600 \mathrm{KN} / \mathrm{M}^{2}$ is shown in Figure 32. Stress distribution for the same loading condition for CFRP strengthened masonry wall are shown in Figures 33 through 34, and for a GFRP strengthened masonry wall are shown in Figures 36 through 38 while for AFRP strips the stress distribution results are shown in Figures 39 through 41. Finally, stress distributions for unstrengthened masonry wall for a distributed load of $800 \mathrm{KN} / \mathrm{M}^{2}$ is shown in Figure 42 and for FRP strengthened masonry wall are shown in Figures 43 through 51 .
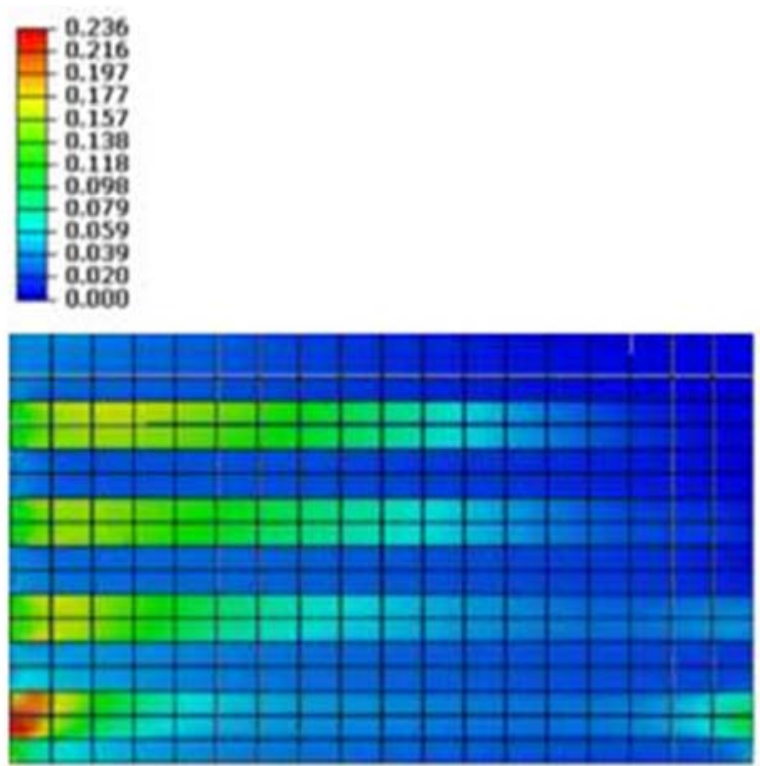

Figure 23. Stresses in Masonry Wall (MPa) Strengthened with Horizontal CFRP strips.
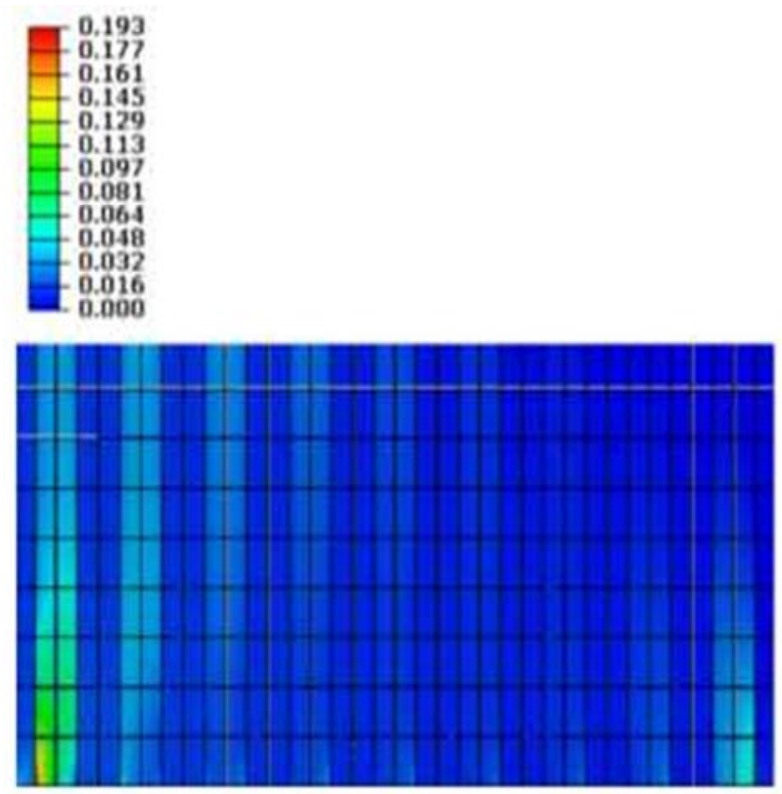

Figure 24. Stresses in Masonry Wall (MPa) Strengthened with Vertical CFRP strips.

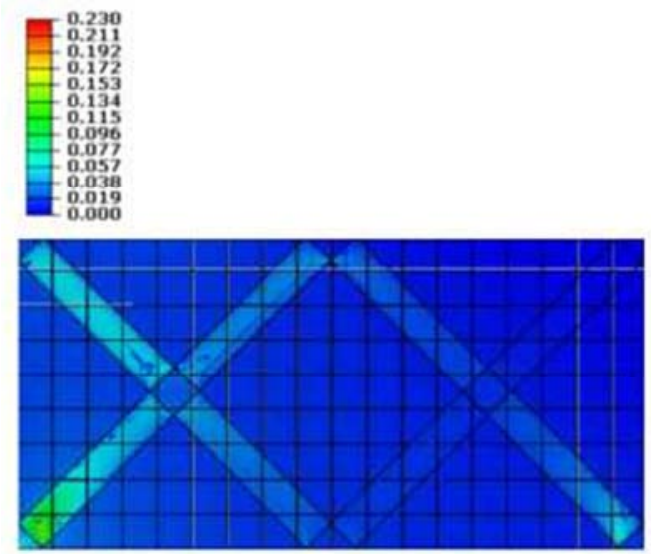

Figure 25. Stresses in Masonry Wall (MPa) Strengthened with Cross Grid CFRP Strips.

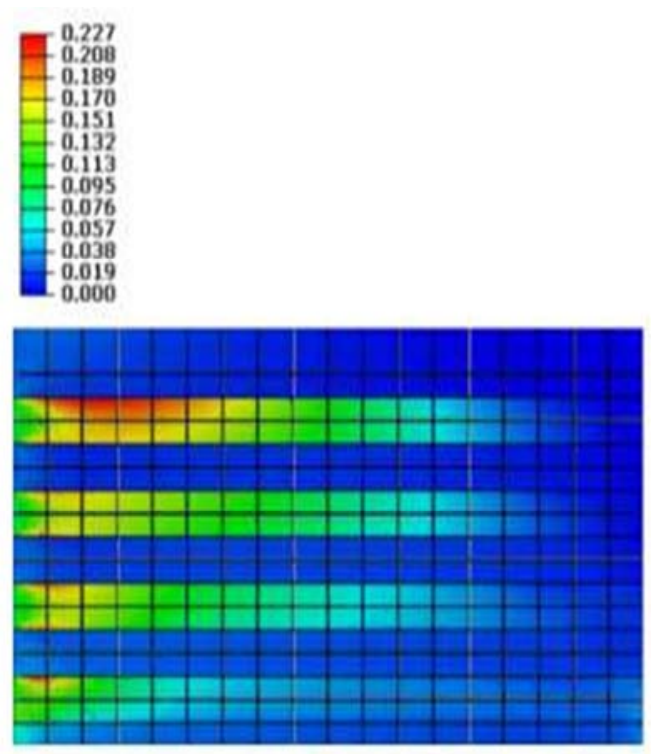

Figure 26. Stresses in Masonry Wall (MPa) Strengthened with Horizontal GFRP strips.
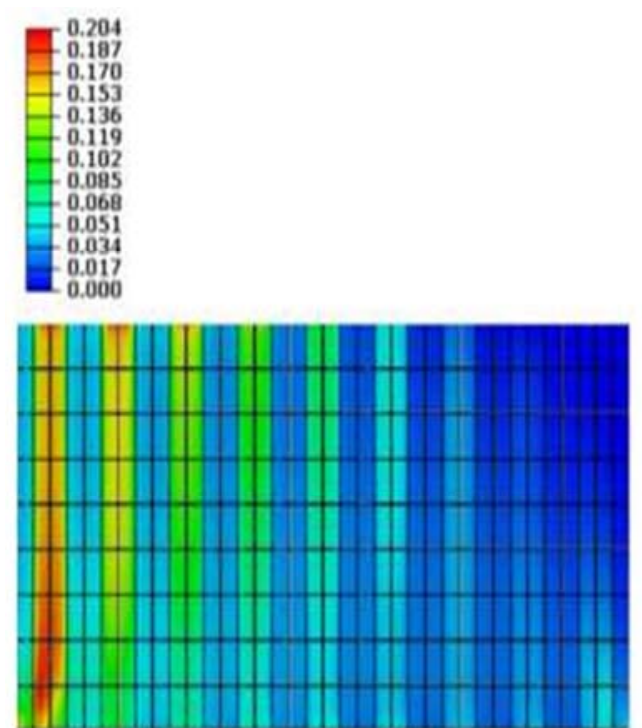

Figure 27. Stresses in Masonry Wall (MPa) Strengthened with Vertical GFRP strips. 


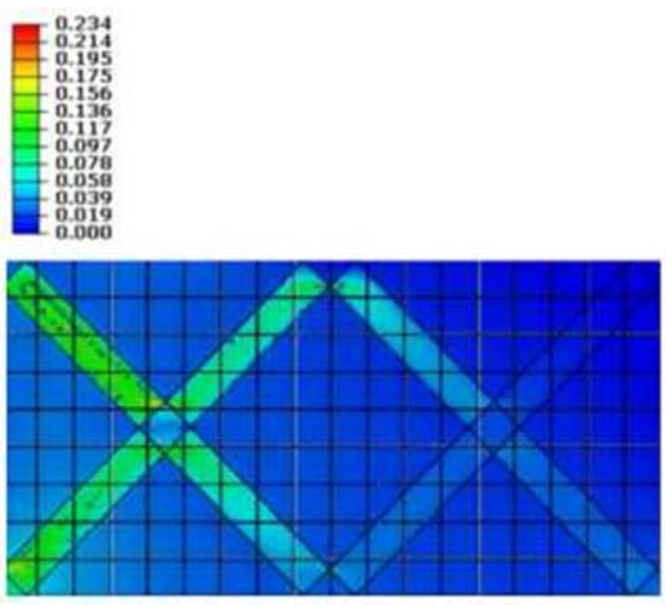

Figure 28. Stresses in Masonry Wall (MPa) Strengthened with Cross Grid GFRP Strips.
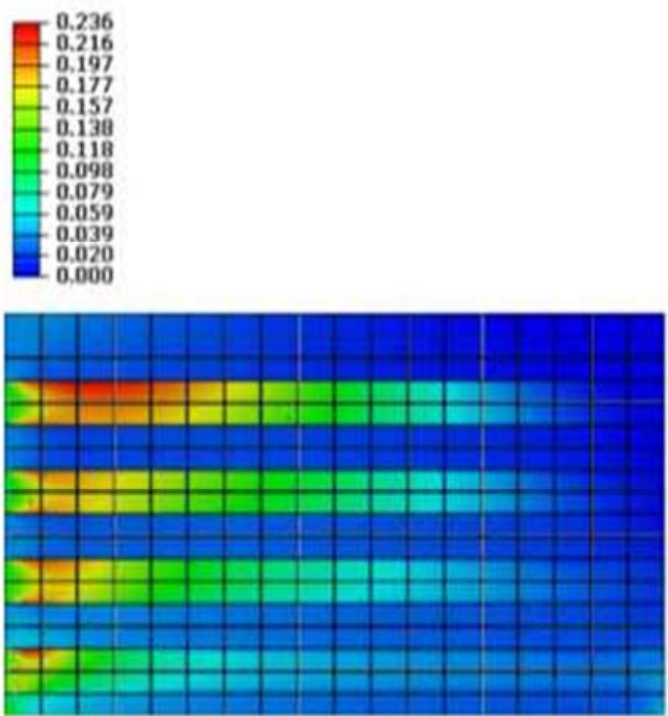

Figure 29. Stresses in Masonry Wall (MPa) Strengthened with Horizontal AFRP strips.

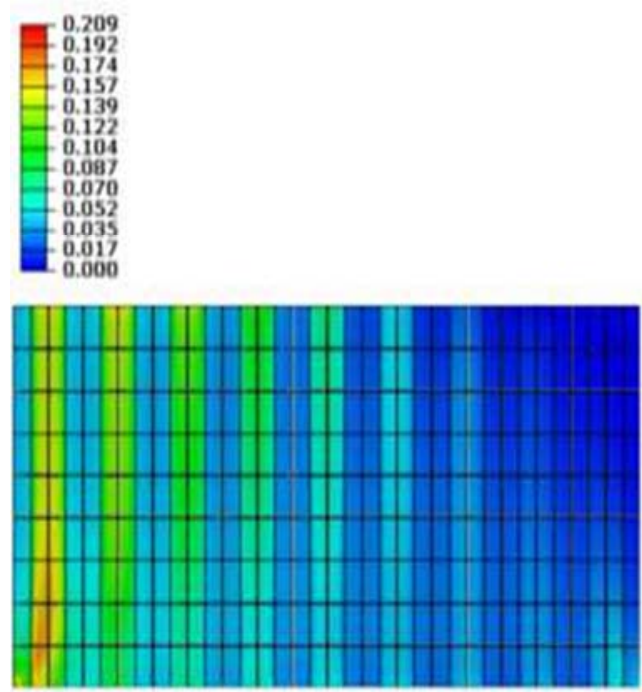

Figure 30. Stresses in Masonry Wall (MPa) Strengthened with Vertical AFRP strips.

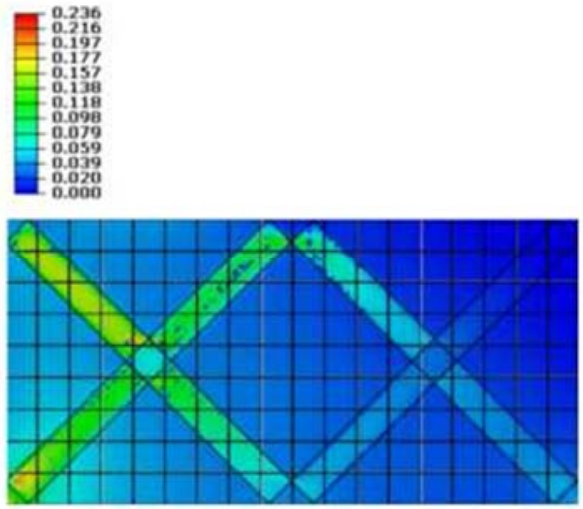

Figure 31. Stresses in Masonry Wall (MPa) Strengthened with Cross Grid AFRP Strips.

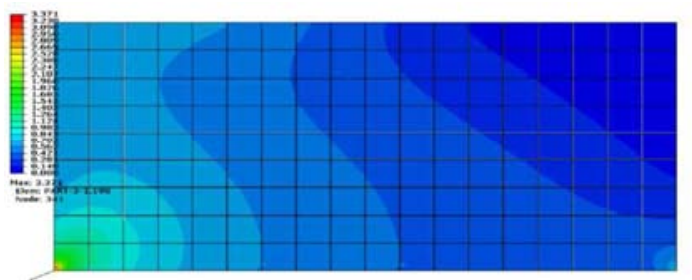

Figure 32. Stresses in Unreinforced Masonry Wall (Mpa) subjected to a uniform load of $600 \mathrm{KN} / \mathrm{M} 2$.

Note: All walls in Figures 5-33 5-32 through 5-41 are subjected to a uniformly distributed load of $600 \mathrm{KN} / \mathrm{M}^{2}$.

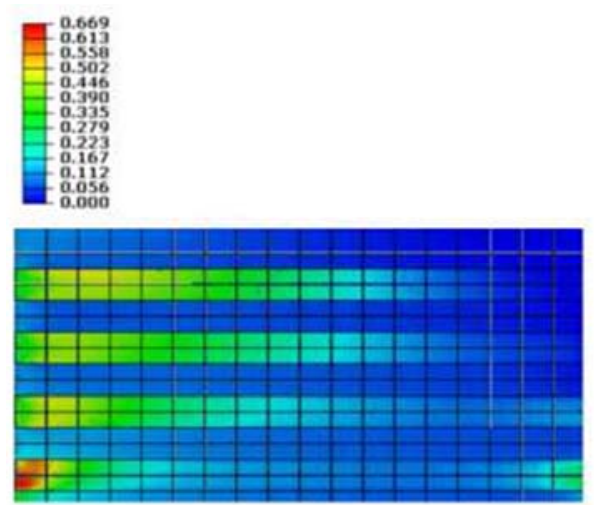

Figure 33. Stresses in Masonry Wall (MPa) Strengthened with Horizontal CFRP strips.

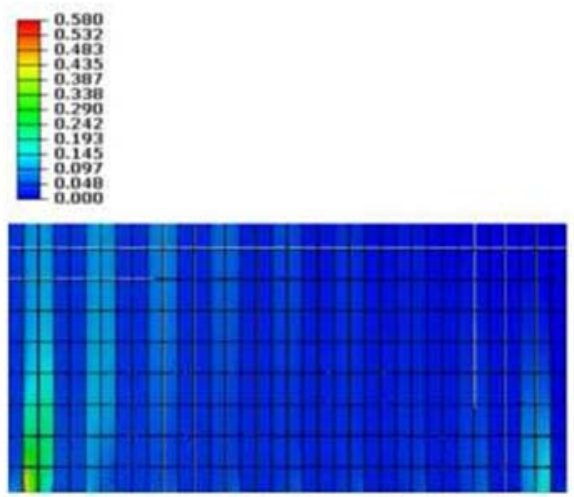

Figure 34. Stresses in Masonry Wall (MPa) Strengthened with Vertical CFRP strips. 


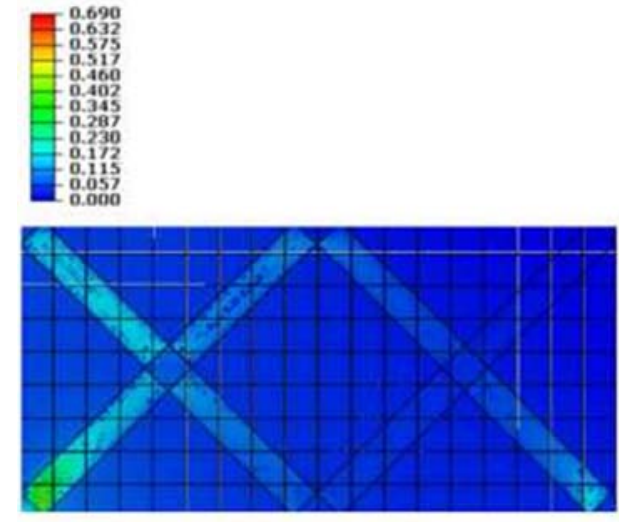

Figure 35. Stresses in Masonry Wall (MPa) Strengthened with Cross Grid CFRP Strips.

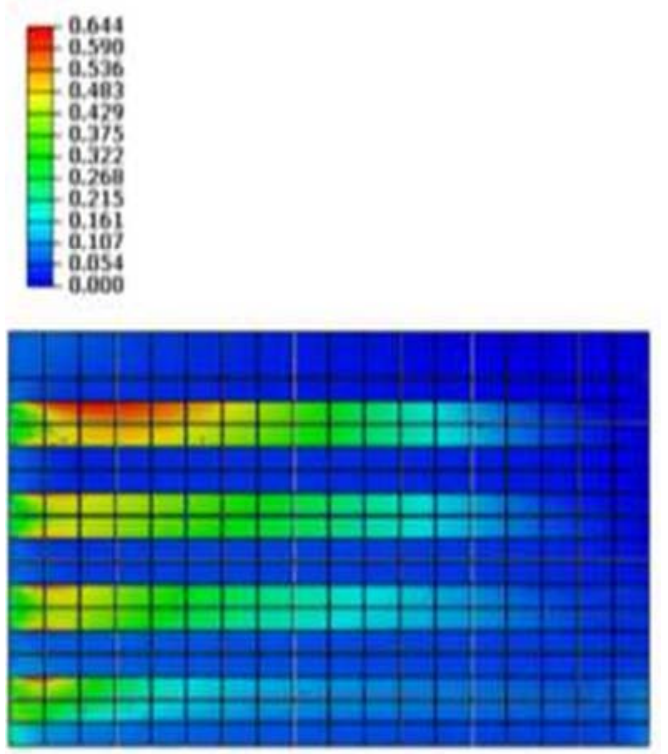

Figure 36. Stresses in Masonry Wall (MPa) Strengthened with Horizontal GFRP strips.

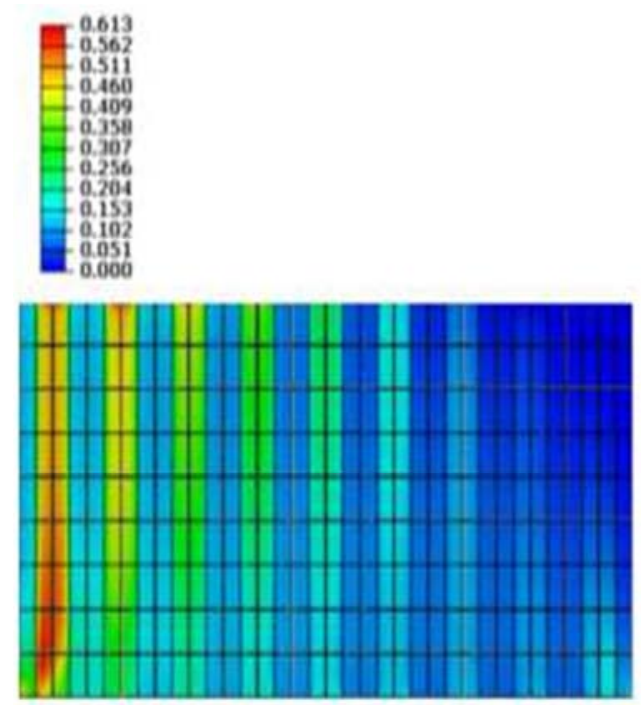

Figure 37. Stresses in Masonry Wall (MPa) Strengthened with Vertical GFRP strips.

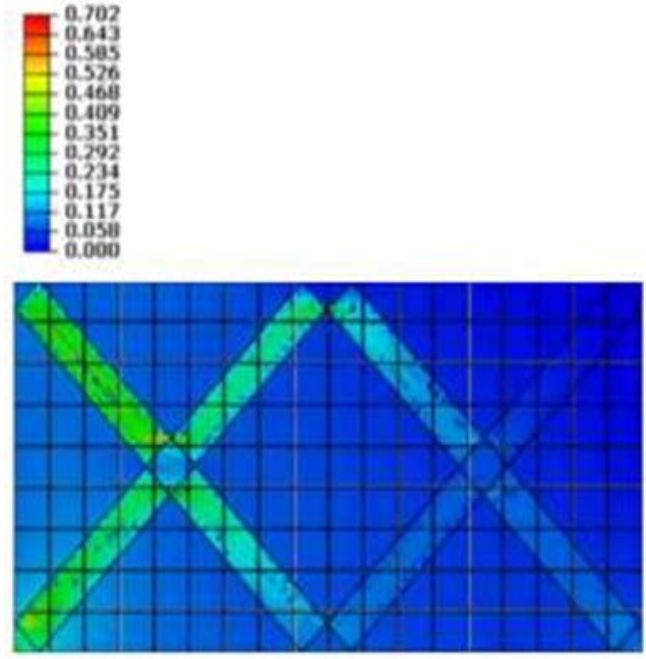

Figure 38. Stresses in Masonry Wall (MPa) Strengthened with Cross Grid GFRP Strips.

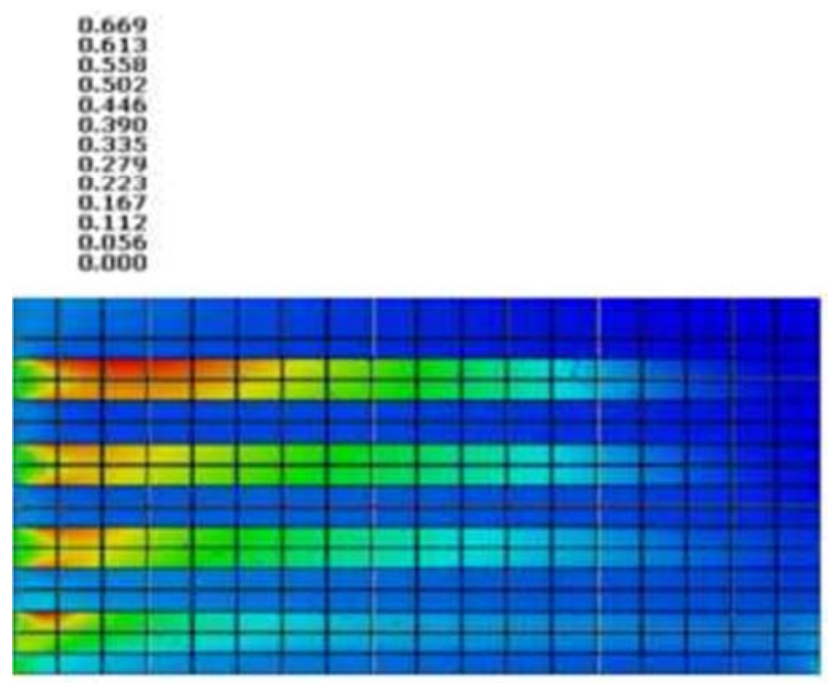

Figure 39. Stresses in Masonry Wall (MPa) Strengthened with Horizontal AFRP strips.

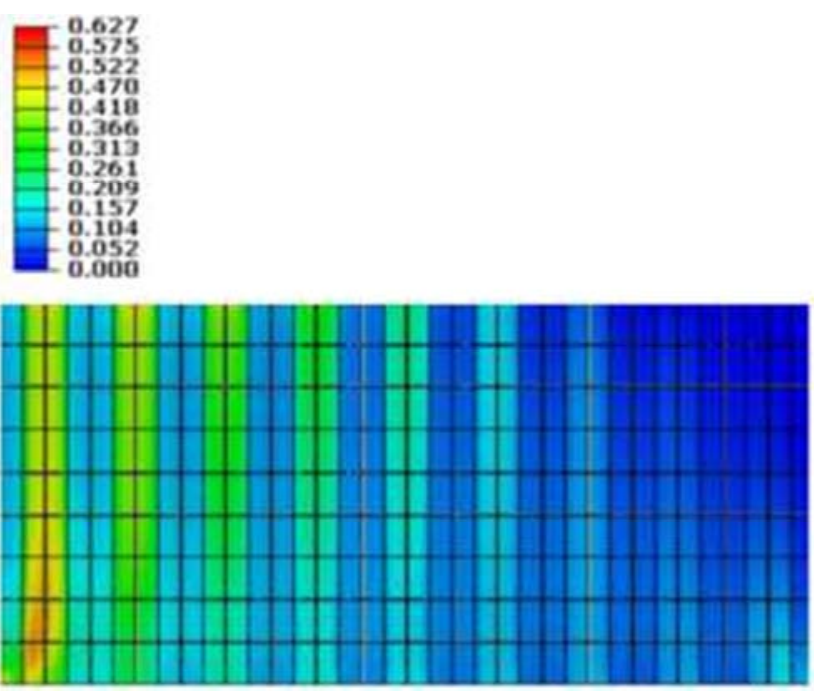

Figure 40. Stresses in Masonry Wall (MPa) Strengthened with Vertical AFRP strips. 


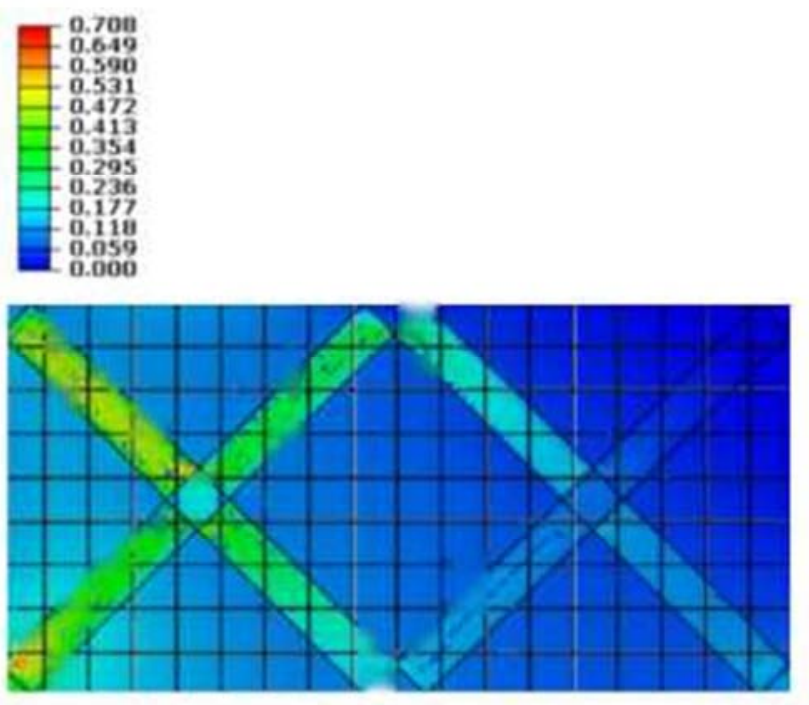

Figure 41. Stresses in Masonry Wall (MPa) Strengthened with Cross Grid AFRP Strips.

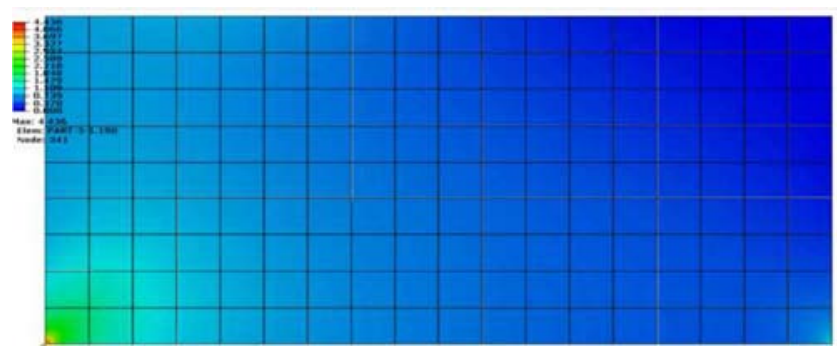

Figure 42. Stresses in Unreinforced Masonry Wall (Mpa) subjected to a uniformly distributed load of $800 K N / M^{2}$.

Note: All walls in Figures 5-43 through 5-51 are subjected to a uniformly distributed load of $800 \mathrm{KN} / \mathrm{M}^{2}$.
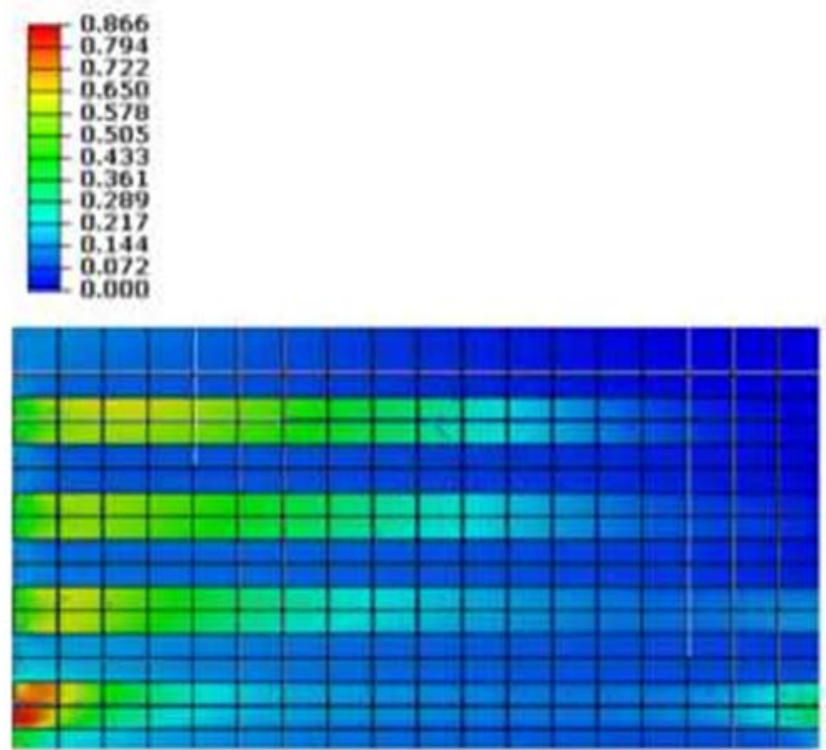

Figure 43. Stresses in Masonry Wall (MPa) Strengthened with Horizontal CFRP strips.

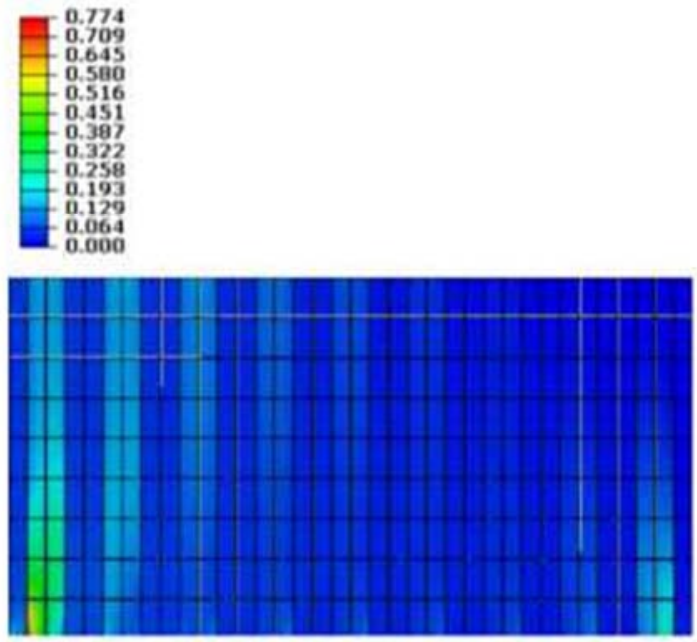

Figure 44. Stresses in Masonry Wall (MPa) Strengthened with Vertical CFRP strips.

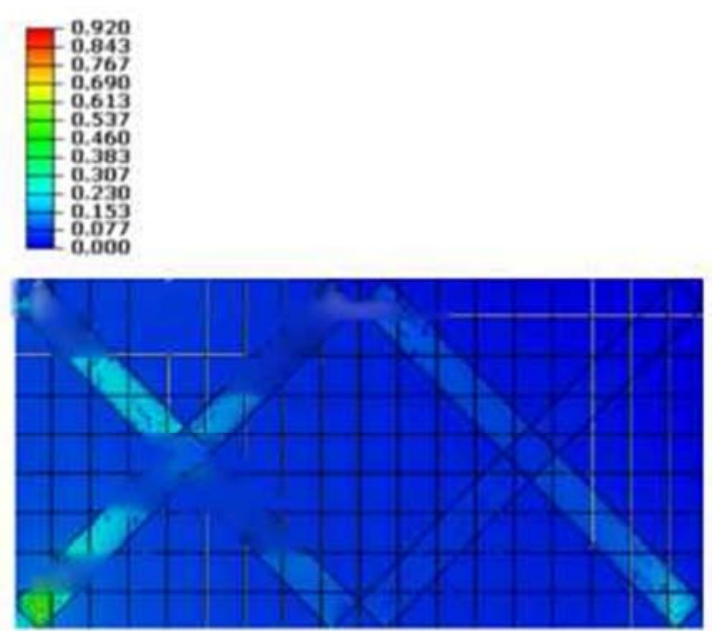

Figure 45. Stresses in Masonry Wall (MPa) Strengthened with Cross Grid CFRP Strip.
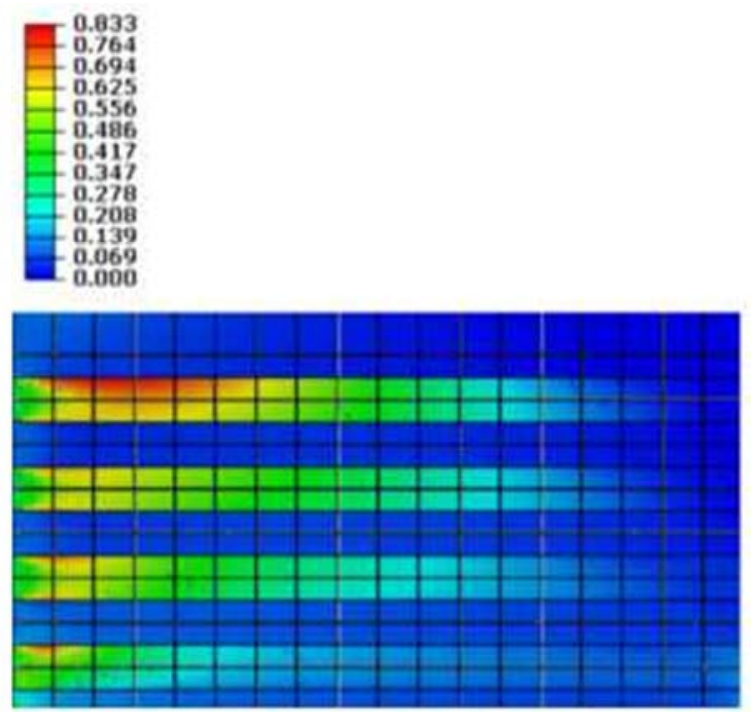

Figure 46. Stresses in Masonry Wall (MPa) Strengthened with Horizontal GFRP strips. 


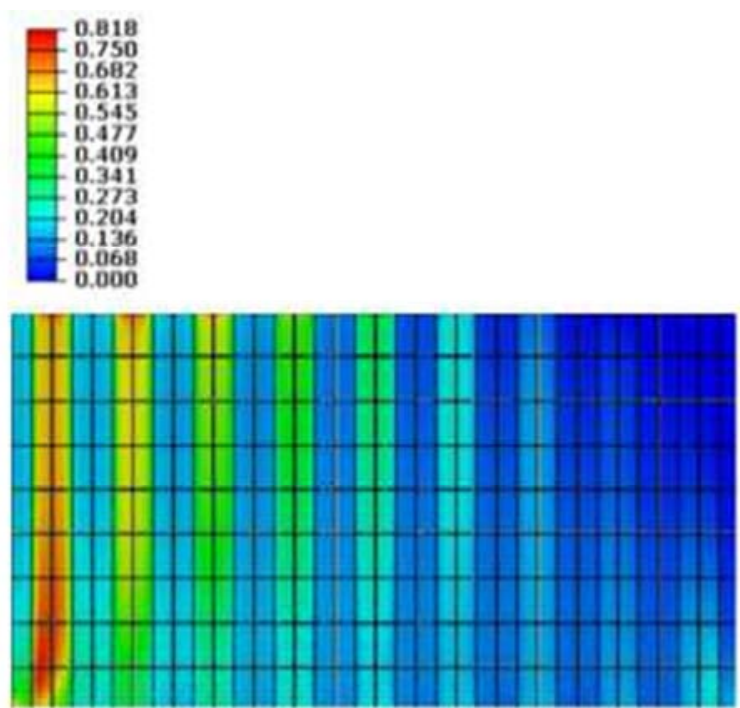

Figure 47. Stresses in Masonry Wall (MPa) Strengthened with Vertical GFRP strips.
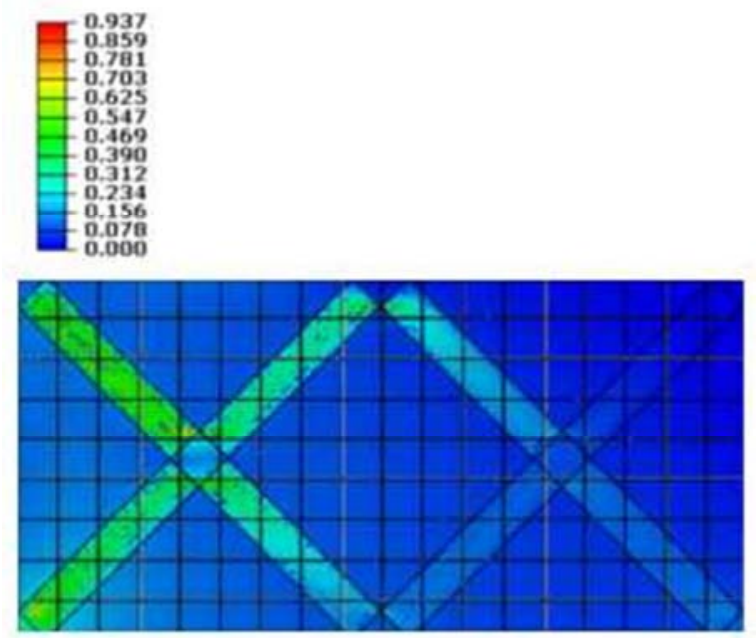

Figure 48. Stresses in Masonry Wall (MPa) Strengthened with Cross Grid GFRP Strip
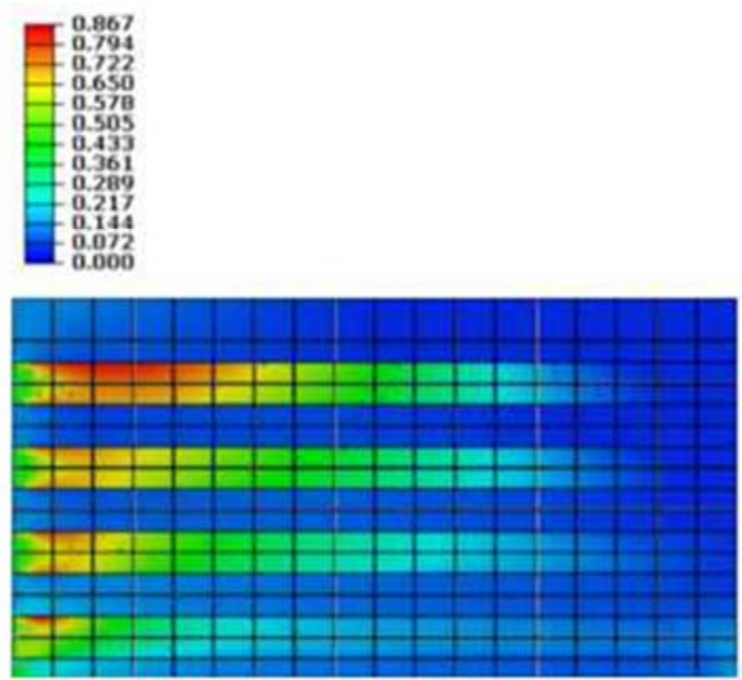

Figure 49. Stresses in Masonry Wall (MPa) Strengthened with Horizontal AFRP strips.
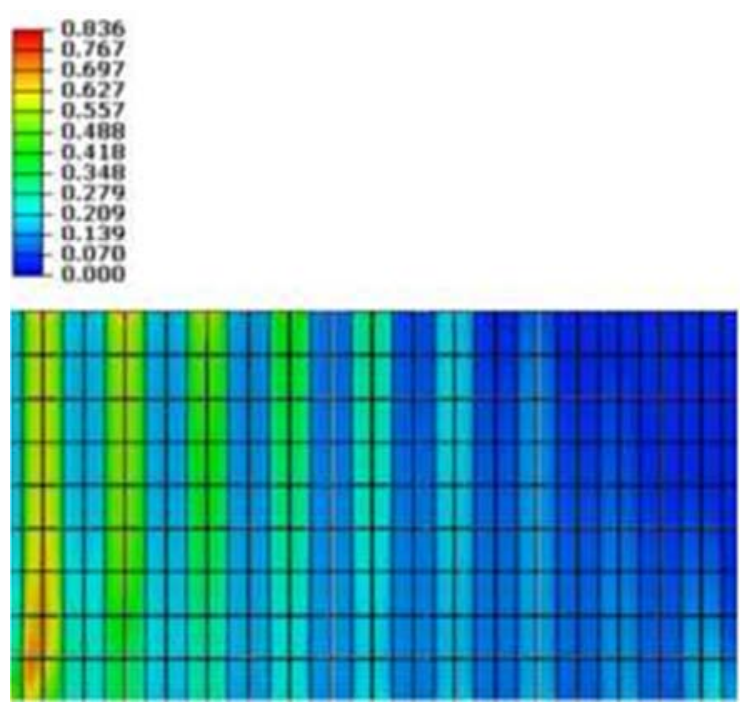

Figure 50. Stresses in Masonry Wall (MPa) Strengthened with Vertical AFRP strips.
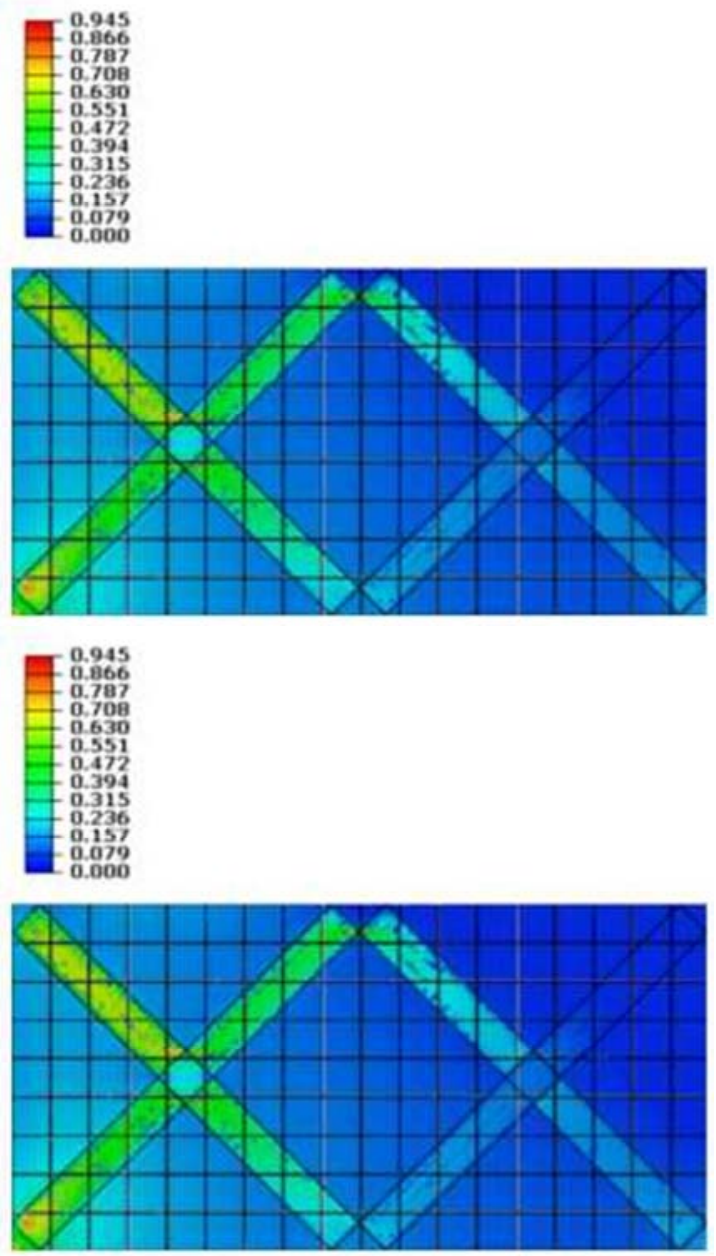

Figure 51. Stresses in Masonry Wall (MPa) Strengthened with Cross Grid AFRP Strip

In all load cases, it can be seen that there is a significant decrease in stresses in the FRP strengthened masonry walls. Therefore the tensile stresses were transferred from the masonry walls to the FRP grids. For the unreinforced wall the 
zone of maximum tensile stress was on the lower left corner while for the reinforced wall the zone of maximum tensile stress started at the lower left corner and migrated upwards. It is important to note that masonry walls strengthened with vertical CFRP strips transferred the most tensile stresses in all load cases therefore the most efficient FRP type and pattern.

\section{Conclusion}

The goal of this paper is to model the behavior of unreinforced and FRP strengthened masonry wall subject to in-plane loading with finite element modeling. Models have been employed to carry out to a numerical study regarding the load carrying capacity generated through FRP strengthening. The dominant mechanical parameters chosen for the formulation are the elasto-plastic properties of the mortar joint, namely cohesion and friction.

The results demonstrate that tensile stresses are transferred from masonry to the FRP stripes leading to a reduction in masonry stresses. The zone of maximum tensile stress occurs in the lower left corner of the wall and migrates up. The analysis also shows that CFRP and GFRP composites provide greater advantages in strengthening of masonry walls by increasing the shear strength of masonry the most. The results also showed that the vertical grid pattern produced the highest increase in the load carrying capacity of the FRP strengthening. Therefore, the vertical grid pattern is the most commonly used in practice. Future research should involve verification of the numerical model through laboratory tests and studies conducted on existing buildings.

\section{References}

[1] ABAQUS (2015). Software. (Version 6.14) USA: Dassault Systems Simulia Corp.

[2] Abrams, D. and Lynch, J. (2001). "Flexural behavior of retrofitted masonry piers." In Korea Earthquake Engineering Research Center (KEERC)-Mid America Earthquake Center (MAE) Joint Seminar on Risk Mitigation for Regions of Moderate Seismicity. Urbana, Ill.

[3] Alcaino, P. and Santa-Maria, H. (2008). "Experimental Response of Externally Retrofitted Masonry Walls Subjected to Shear Loading." J. Compos. Constr., 12, 5, 489-498.

[4] Ehsani, M. R. Saadamanesh, H. and Valazquez-Dimas, J. (1999). "Behavior of Retrofitted URM Walls Under Simulated Earthquake Loading." Journal of Composites for Construction, 134-141.

[5] ElGawady, M., Lestuzzi, P., and Badoux, M. (2005). "Rehabilitation of unreinforced brick masonry walls using composites." Carbon, 93, 2800, 1-11.

[6] Garbin, E., Valluzzi, M., Modena, C., Galati, N., and Nanni, A. (2006). "In-plane design for masonry walls strengthened by FRP materials." In Proceedings of the 11th International Conference: Structural Faults \& Repair, vol. 184. [CD-ROM version], UK.
[7] Hamid, A., El-Dakhakhani, W., Hakam, Z., and ElGawady, M. (2005). "Behavior of Composite Unreinforced Masonry-Fiber-Reinforced Polymer Wall Assemblages Under In-Plane Loading.” Journal of Composites for Construction, 9, $1,73-83$.

[8] Haroun, M., Mosallam, A., and Allam, K. (2001). "Cyclic In-Plane Shear of Concrete Masonry Walls Strengthened by FRP Laminates." In Proceedings of Seventh International Symposium on Fiber Reinforced Polymers for Reinforced Concrete Structures, vol. SP-230-19, 327-339. ACI, Kansas City.

[9] Li, T., Silva, P., Belarbi, A., and Myers, J. (2001). "Retrofit of Un-Reinforced Infill Masonry Walls with FRP.” In Proceedings of the Composites in Construction.

[10] Lopez, J., Oller, S., Onate, E., and Lubliner, J. (1999). “A homogeneous constitutive model for masonry.” Int. J. Numer. Meth. Eng., 46, 1651-1671.

[11] Lourenco, P. (1998). "Experimental and numberical issues in the modelling of the mechanical behaviour of masonry." Journal of Structural Analysis of Historical Constructions II, CIMNE, 1-35.

[12] Page, A. (1978). "Finite element model for masonry." J. Struct. Div., ASCE, 104, 8, 1367-1285.

[13] Paulay, T. and Priestley, M. (1992). Seismic Design of Reinforced Concrete and Masonry Buildings. New York: J. Wiley.

[14] Schwegler, G. (1994). Masonry construction strengthened with fiber composites in seismically endangered zones, vol. 2299-2303. Vienna: ECEE.

[15] Shing, P., Lofti, H., Barzegarmehrabi, A., and Brunner, J. (1992). "Finite element analysis of shear resistance of masonry wall panels with and without confining frames." In Proc. 10th World Conf. on Earthquak Engrg., ed. A. Balkema, 2581-2586. Rotterdam, The Netherlands.

[16] Suidan, M. and Schnobrich, W. (1973). "Finite element analysis of reinforced concrete." J. Struct. Engnr. ASCE, 99, $10,2109-2122$.

[17] Tomazevic, M. (2000). Earthquake-Resistant Design of Masonry Buildings. Imperial College Press. Pp. 268.

[18] Tumialan, G., Morbin, A., Nanni, A., and Medena, C. (2001). "Shear Strength of Masonry Walls with FRP Composites." In COMPOSITES 2001 convention and Trade Show, Composites Fabricators Association, 6.

[19] Turek, M., Ventura, C., and Kuan, S. (2007). "In-Plane Shake-Table Testing of GFRP-Strengthened Concrete Masonry Walls.” Earthquake Spectra, 23, 1, 223-237.

[20] Valluzzi, M., Tinazzi, D., and Modena, C. (2002). "Shear behaviour of masonry panels strengthened by FRP laminates." Const. and Building Mat., 16, 409-416.

[21] Yu, P., Silva, P., and Nanni, A. (2004). "Application of bond polyurea in structural strengthening of RC beams and UMR walls." Final Report CIES 01-49, University of Missouri-Rolla, Center for Infrastructure Engineering Studies. 